\section{Applying the Stress Process Model to Stress-Burnout and Stress-Depression Relationships in Biomedical Doctoral Students: A Cross-Sectional Pilot Study}

\author{
Alexander J. Hish, ${ }^{\dagger}$ Gabriela A. Nagy, ${ }^{+}$Caitlin M. Fang, ${ }^{\dagger}$ Lisalynn Kelley, ${ }^{\dagger}$ \\ Christopher V. Nicchitta, ${ }^{\ddagger}$ Kafui Dzirasa, ${ }^{\dagger}{ }^{\dagger \mid \pi}$, and M. Zachary Rosenthal ${ }^{\dagger \# *}$ \\ ${ }^{\dagger}$ Department of Psychiatry and Behavioral Sciences, "Department of Cell Biology, Office of \\ Biomedical Graduate Education, ${ }^{\$}$ Center for Neuroengineering, and "Duke Institute for Brain \\ Sciences, Duke University Medical Center, Durham, NC 27710; 'Departments of Biomedical \\ Engineering and Neurobiology and \#Department of Psychology and Neuroscience, Duke \\ University, Durham, NC 27710
}

\begin{abstract}
Although doctoral students in the biomedical sciences have been recognized as a population at particular risk for mental health problems such as burnout and depression, little research has been conducted to identify candidate targets for intervention. To this end, we used the stress process model to evaluate potential mediators of stress-burnout and stress-depression relationships in biomedical doctoral students. A cross-sectional sample ( $n=69$ ) completed validated self-report measures of stress; symptoms of burnout and depression; and perceptions of mastery, social support, and advisor support. In linear regression models, we found that academic stressors were most predictive of burnout, whereas family/monetary stressors were most predictive of depression. In mediation models, we found that the relationship between stress and burnout was partially mediated by mastery and advisor support, while the stress-depression relationship was partially mediated by mastery. These findings represent a first step in identifying interventional targets to improve mental health in this at-risk population. Whereas certain stressors are inherent to the doctoral training environment, psychosocial interventions to enhance one's sense of mastery and/or to improve advisor relationships may mitigate the influence of such stressors on burnout and depression.
\end{abstract}

\section{INTRODUCTION}

In recent years, large national and international survey studies have begun validating anecdotal reports of significant mental health challenges across doctoral student populations, indicating heightened risk for problems including depression, anxiety, and burnout (e.g., Levecque et al., 2017; Evans et al., 2018). More specifically, doctoral students in the biomedical sciences have been recognized as a population at particular risk for mental health problems, yet remain understudied (Tsai and Muindi, 2016). Addressing this issue is an important area of concern for the well-being of individuals undertaking careers in biomedical science, as well as the future of the broader biomedical enterprise. To this point, poor mental health in doctoral student samples has been associated with reduced academic productivity, decreased quality of work, and attrition (Hyun et al., 2006; Levecque et al., 2017).

Despite this increasing scholarly interest in doctoral student well-being, little scientific work has been done to identify specific targets for programmatic intervention (Tsai and Muindi, 2016; Evans et al., 2018). To this end, the present study represents a secondary analysis of data derived from a sample of biomedical doctoral students $(n=69)$. Our primary analyses (Nagy et al., 2019) characterized and assessed the
Rebecca Price, Monitoring Editor Submitted Mar 20, 2019; Revised Aug 13, 2019; Accepted Aug 20, 2019

CBE Life Sci Educ December 1, 2019 18:ar51 DOI:10.1187/cbe.19-03-0060

*Address correspondence to: M. Zachary Rosenthal (mark.rosenthal@aduke.edu)

(c) 2019 A. J. Hish et al. CBE-Life Sciences Education @ 2019 The American Society for Cell Biology. This article is distributed by The American Society for Cell Biology under license from the author(s). It is available to the public under an Attribution-Noncommercial-Share Alike 3.0 Unported Creative Commons License (http://creativecommons.org/licenses/ by-nc-sa/3.0).

"ASCB®" and "The American Society for Cell Biology $\circledR^{\prime \prime}$ are registered trademarks of The American Society for Cell Biology. 
prevalence of problems related to burnout and mental health, as well as associations among burnout, mental health, academic variables, and sociodemographic variables for this population. We documented high rates of mental health problems and urges to drop out of their doctoral programs - a marker of dissatisfaction. Namely, approximately half of the students met criteria for at least one psychiatric diagnosis in the past year, more than two-thirds of students reported thoughts of dropping out, and the majority of students reported some level of burnout. Furthermore, the variables that most meaningfully contributed to burnout included thoughts related to dropping out, poor perceptions of employment opportunities, functional impairment due to a mental health problem, and having at least one current psychiatric disorder.

The results presented in Nagy et al. (2019) documented an important phenomenon that warrants immediate attention. In the present study, we build on the evaluation of associations among burnout, mental health problems, and academic elements by examining mechanisms through which poor mental health may develop in this population. Namely, we use Pearlin and colleagues' model of the stress process (Pearlin et al., 1981; Pearlin and Bierman, 2013) to examine the roles of mastery and social support as possible mediators of both the stressburnout and stress-depression relationships in biomedical doctoral students.

\section{The Stress Process}

Many models and theories have been put forward to describe the complex construct of stress across decades (for further discussion, see Goldstein and Kopin, 2007; Koolhaas et al., 2011; Wheaton et al., 2013). One influential model is the stress process, which has served as a framework for understanding mechanisms by which stressors lead to health outcomes (Pearlin et al., 1981; Pearlin, 2009; Wheaton, 2009; Aneshensel and Mitchell, 2014). This model distinguishes between three elements of stress: sources (e.g., life events, chronic stressors), outcomes (e.g., mental and physical health problems), and mediators (e.g., self-concepts, social support, coping skills; Pearlin, 1989, 2009). The stress process model has garnered substantial empirical support and has been applied across a wide range of samples (e.g., students, employees; Attell et al., 2017; Dupéré et al., 2015). Despite its utility in identifying the mechanisms linking stressors to outcomes, to our knowledge, this model has never been applied to understanding the stress process in biomedical doctoral students.

\section{Sources of Stress}

Although everyday stress does not always harm the individual and may be adaptive, chronic and pathological stress can result in negative physical and mental health outcomes (Schneiderman et al., 2005; Thoits, 2010). Doctoral students face many potential chronic stressors, including demanding work hours (Ferreira, 2003), poor work-life balance (Fuhrmann et al., 2011), economic hardship (Hyun et al., 2006), and uncertain employment prospects (Alberts et al., 2014). Doctoral students in the biomedical sciences may endure these and other stressors shared across many kinds of graduate training programs. At the same time, they may experience particular stressors more common among those in biomedical training programs.

\section{Outcomes of Stress}

Two related but different adverse outcomes of stress are burnout (Maslach et al., 2001) and depression (Hammen, 2005). Burnout encompasses three responses to chronic job-related stress: 1) emotional exhaustion, 2) depersonalization or cynicism, and 3) reduced personal accomplishment or professional inefficacy (Maslach et al., 1986; Schaufeli et al., 2009). Symptoms of depression, including depressed mood and anhedonia, are outlined in the Diagnostic and Statistical Manual of Mental Disorders (American Psychiatric Association, 2013). There may be some overlap between burnout and depression, considering, for example, some shared etiological factors and symptoms (e.g., Bianchi et al., 2015, 2017; Maslach and Leiter, 2016). However, the spectrum of depressive symptoms extends beyond those of burnout, and although these constructs are related, they are distinct.

Initially thought to apply chiefly to service professions, burnout has become an increasingly recognized phenomenon in higher education, including among doctoral students (e.g., Parker and Salmela-Aro, 2011; Cornér et al., 2017; Peltonen et al., 2017). Similarly, depressive symptoms are common among doctoral students, with reported prevalence estimates of depressive disorders as high as 32-39\% (Levecque et al., 2017; Evans et al., 2018).

The Relationship between Stress and Burnout. Burnout has long been understood as an outcome of prolonged, unresolvable, work-related stress (Schaufeli and Enzmann, 1998; Bakker and Demerouti, 2007; Maslach and Leiter, 2016). Although the presence of this relationship in biomedical doctoral students has not been studied, burnout has been linked to stress in other doctoral student samples. For example, Clark et al. (2009) found that, in a sample of counseling psychology doctoral students, global stress (e.g., "In the last month, how often have you dealt successfully with life tasks?"; Cohen et al., 1983) was a significant predictor of burnout.

The Relationship between Stress and Depression. Stressors also may play an important role in the etiology of depression, as evidenced by the finding that individuals who report chronic stress (especially characterized by perceptions of loss of control, entrapment, and loss of status) are more likely to be diagnosed with a depressive disorder (Mazure, 1998; Hammen, 2005; Pizzagalli, 2014). Additionally, evidence indicates that stress leads to a subjective experience of depression (Hammen, 2005), objective measures of depression (e.g., Leskela et al., 2006; Hawley et al., 2007), and physiological changes thought to underlie depression (Pizzagalli, 2014). The link between stress and depressive disorders has not been explicitly studied in biomedical doctoral students, though one study involving a mixed sample of doctoral students connected academic stress to suicidal ideation (You and Chen, 2012). In addition, the stress-depression association is well established among medical students, who face many challenges similar to those experienced by doctoral students, including excess workload, a potentially abusive training environment, and financial hardship (Dyrbye et al., 2005).

\section{Mediators of Stress}

Mastery as a Mediator in the Stress-Outcome Relationship. Mastery-an aspect of an individual's self-concept 
encompassing the extent to which an individual regards his or her circumstances as under his or her control-has been well studied as a mediator of stress-outcome relationships (e.g., Pudrovska et al., 2005; Aneshensel and Mitchell, 2014; Nicolaisen et al., 2017). Stress process theory proposes that chronic stress diminishes a person's sense of mastery, thus putting that person at risk for subsequent outcomes such as depression (Aneshensel and Mitchell, 2014). Consistent with this model, reduced mastery has been shown to be predictive of depressive symptoms in individuals at high risk for stress, including caregivers (Mausbach et al., 2007). In doctoral students, self-efficacy (a construct related to mastery insofar as it measures perceived control; see Berry and West, 1993) is negatively correlated with both stress and burnout, suggesting its role as a candidate mediator in the stress-burnout relationship for this population (Rigg et al., 2013; Jenaabadi et al., 2017).

Social Support as a Mediator in the Stress-Outcome Relationship. While levels of social support may directly impact such outcomes as depression and anxiety (Zimet et al., 1988), empirical studies have also shown that stress may deplete one's social resources, indicating social support may be another potential mediator in stress-outcome relationships (e.g., Cohen and Wills, 1985; Cohen, 2004). For example, stress in the form of discrimination predicts lower perceived social support among African-American undergraduate students, which in turn predicts greater symptoms of depression (Prelow et al., 2006). Doctoral students may experience several sources of social support, from their faculty advisors to their peers to their friends and family (Clark et al., 2009; Tompkins et al., 2016). Dysfunctional advisor relationships, involving issues ranging from inadequate frequency of advising to mistreatment, have frequently been linked to doctoral student burnout (e.g., Cornér et al., 2017; Devine and Hunter, 2017; Peltonen et al., 2017) and depressive symptoms (e.g., Evans et al., 2018). Additionally, students with less support in their personal lives (including from family, friends, and significant others) have higher rates of depressive symptoms (e.g., Zimet et al., 1988; Hefner and Eisenberg, 2009; Wang et al., 2014).

\section{Study Aims and Hypotheses}

As previously highlighted, biomedical doctoral students are an understudied population who train in a highly competitive and demanding environment, and the links between stress and stress outcomes have not been well established in this population. Gaining this additional knowledge could guide future longitudinal study and intervention testing to support biomedical doctoral student well-being. To address these gaps in knowledge, this investigation represents the first application of a stress process model to the study of burnout and depression in biomedical doctoral students, using cross-sectional self-report data regarding various dimensions of mental health and well-being. The aims of the present study were to 1) characterize sources of stress and their contributions to burnout and depression, 2) test theoretical links between stress and burnout, and 3) test theoretical links between stress and depression. Specifically, we hypothesized that mastery and social support would be mediators of both the stressburnout and stress-depression relationships in biomedical doctoral students.

\section{METHODS}

\section{Approval from the Institutional Review Board}

We were granted approval from our institution's institutional review board (IRB; protocol 2017-0232) to conduct this study. The IRB protocol was approved under the following category: "Research on individual or group characteristics or behavior (including, but not limited to, research on perception, cognition, motivation, identity, language, communication, cultural beliefs or practices, and social behavior)."

\section{Participants and Recruitment}

Study participants $(n=69)$ were biomedical doctoral students at a large research institution in the southeastern United States. The only inclusion criterion was that participants be biomedical doctoral students currently engaged in training within a department in our institution's school of medicine, but not other departments across our institution's research enterprise (arts and sciences, engineering, etc.). Participants were recruited through brochures and flyers, website postings, emails sent to doctoral students, and in-person presentations at group meetings. All students in our institution's biological and biomedical sciences doctoral programs $(N=592)$ were allowed to participate in our study; therefore, our sample comprises $11.6 \%$ of the total number of eligible students at our institution. Upon participant-initiated contact, the study coordinator scheduled a study visit. For additional details on study design and study flow, refer to Nagy et al. (2019).

\section{Study Protocol}

During the study visit, participants were presented with an IRB-approved informed consent. The informed consent packet covered details relating to the purpose of the study, the components of the study visit, an invitation to participate in future studies, risks (e.g., experiencing unpleasant thoughts and emotions) and benefits (e.g., the collective benefit of improving knowledge of student mental health problems at our institution and how to address them) of participating in the study, limits to confidentiality, the process to withdraw from the study (no participants chose to withdraw), and monetary compensation for participation (\$100). All participants were informed that should they start experiencing strong feelings of upset and/or suicidal thoughts during the study visit, a trained professional would be available to speak with them, and if they were at imminent risk of suicide, they would be taken to the nearest hospital emergency department; no participants met either of these conditions through the entire duration of the study. The study visit, which lasted an average of 4 hours, consisted of self-report questionnaires administered through use of an online survey tool (Qualtrics, 2013) on a computer in our laboratory, along with an in-person diagnostic interview. ${ }^{1}$ Participants who were unable to complete the entire study visit in one session were scheduled for a second session. All paper assessment data and research consent forms were kept in a secure locked cabinet in our laboratory, accessible only to approved study team members. All Qualtrics survey data were de-identified and stored electronically on a secure server only accessible to approved study team members.

\footnotetext{
${ }^{1}$ Results from the in-person diagnostic interview were not used in analyses for the present article, but are reported in Nagy et al. (2019).
} 
TABLE 1. Description of measures

\begin{tabular}{|c|c|c|c|c|c|c|}
\hline Measure $^{\mathrm{a}}$ & Construct (subscales) & Items & Scale & $\begin{array}{l}\text { Original study acceptable } \\
\text { psychometrics properties }\end{array}$ & Original study population & $\begin{array}{l}\text { Present study } \\
\text { internal } \\
\text { consistency } \\
\end{array}$ \\
\hline GSI-R ${ }^{b}$ & $\begin{array}{l}\text { Stress (academic, } \\
\text { environmental, } \\
\text { family/monetary) }\end{array}$ & 20 & $1-7$ & $\begin{array}{l}\text { Internal consistency, concurrent } \\
\text { validity, and retest reliability }\end{array}$ & $\begin{array}{l}\text { Master's and doctoral students } \\
\qquad(n=450)\end{array}$ & $\alpha=0.88$ \\
\hline $\mathrm{SBI}^{\mathrm{c}}$ & Burnout & 9 & $1-6$ & $\begin{array}{l}\text { Internal consistency, structural validity, } \\
\text { and convergent validityc }\end{array}$ & $\begin{array}{l}\text { Secondary high school and } \\
\text { vocational school students } \\
(n=1418)\end{array}$ & $\alpha=0.90$ \\
\hline PHQ-9 & Depressive symptoms & 9 & $0-3$ & $\begin{array}{l}\text { Internal consistency, construct validity, } \\
\text { criterion validity, sensitivity, and } \\
\text { specificity }^{\mathrm{d}}\end{array}$ & $\begin{array}{l}\text { Primary care and obstetrics- } \\
\text { gynecology clinic patients } \\
(n=6000)\end{array}$ & $\alpha=0.89$ \\
\hline Mastery $^{e}$ & Mastery & 7 & $1-4$ & $\begin{array}{l}\text { Internal validity, construct validity, and } \\
\text { predictive validity }{ }^{f}\end{array}$ & $\begin{array}{l}\text { Adult heads of households } \\
\qquad(n=2300)\end{array}$ & $\alpha=0.79$ \\
\hline MSPSSg & Social support & 12 & $1-7$ & $\begin{array}{l}\text { Internal consistency, test-retest } \\
\text { reliability, and construct validity }\end{array}$ & $\begin{array}{l}\text { Undergraduate students } \\
\qquad(n=275)\end{array}$ & $\alpha=0.87$ \\
\hline AWAI $^{\text {h }}$ & Advisor relationship & 30 & $1-5$ & $\begin{array}{l}\text { Internal consistency, internal validity, } \\
\text { and test-retest reliability }{ }^{\mathrm{h}}\end{array}$ & $\begin{array}{l}\text { Students in counseling psychol- } \\
\text { ogy doctoral programs } \\
\quad(n=281)\end{array}$ & $\alpha=0.85$ \\
\hline
\end{tabular}

aAbbreviations: AWAI, Advisory Working Alliance Inventory-Student Version; GSI-R, Graduate Stress Inventory-Revised ; Mastery, Pearlin Mastery Scale; MSPSS, Multidimensional Scale of Perceived Social Support; PHQ-9, Patient Health Questionnaire-9; SBI, School Burnout Inventory. Modified or freely available measures have been reproduced in the Supplemental Material.

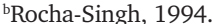

"Salmela-Aro et al., 2009 (original measure was modified in the following manner: "schoolwork" replaced with "graduate program" on every item).

dKroenke et al., 2001.

ePearlin et al., 1991.

fMarshall and Lang, 1990.

¿Zimet et al., 1988.

${ }^{\mathrm{h} S}$ Schlosser and Gelso, 2001.

\section{Data Integrity Procedures}

We underwent several processes to ensure integrity of self-report data. During the study visit, the assessor was available to provide clarity regarding the content of specific items and offer breaks as needed. We downloaded de-identified self-report data from Qualtrics into the Statistical Package for Social Sciences (SPSS; IBM Corporation, 2015). We created syntax to compute total scale and subscale scores on our measures, per instructions from developers of each measure when applicable. We subsequently ran frequencies on all variables of interest to identify and correct errors in data collection to determine whether all data values fell within the possible response parameters.

\section{Measures}

Table 1 presents a summary of the measures used in this study, including previously reported psychometric properties, ${ }^{2}$ original study population, and internal consistency ${ }^{3}$ (i.e., Cronbach's $\alpha$ ) in the present study. Full measures are included in the Supplemental Material.

Stress. To assess the presence and severity of participants' stress, we used the Graduate Stress Inventory-Revised (GSI$\mathrm{R}$; Rocha-Singh, 1994). The GSI-R is a 20 -item self-report instrument assessing the degree to which circumstances and

${ }^{2}$ Criterion, concurrent, and predictive validity assess how well the measure correlates with or predicts scores on previously validated measures. Structural, construct, and convergent validity assess the degree to which the survey measures what it claims to. Retest or test-retest reliability refers to the agreement between successive administrations of the same measure.

${ }^{3}$ Internal consistency refers to how closely the items in a measure are related. experiences in a graduate student's life (e.g., taking exams, meeting with faculty) are perceived as stressful. Participants rate the extent to which a number of potential stressors impact their lives. Items are rated on a 1 (not at all stressful) to 7 (extremely stressful) scale, and higher scores indicate greater perceptions of stress. The scale produces three subscales: Academic Stress, Environmental Stress, and Family/ Monetary Stress.

Burnout. To quantify burnout, we used a modified version of the School Burnout Inventory (SBI; Salmela-Aro et al., 2009). The SBI used herein is a nine-item self-report measure that assesses clinically relevant indices of burnout in the context of one's graduate program, including exhaustion due to graduate work, cynicism toward the meaning of graduate school, and sense of inadequacy at graduate school. Items are rated on a 1 (completely disagree) to 6 (completely agree) scale, and higher scores indicate greater burnout symptoms.

Depressive Symptoms. To assess the presence and severity of depressive symptoms, we used the Patient Health Questionnaire-9 (PHQ-9; Kroenke et al., 2001). Participants rate the frequency at which they experience symptoms of major depression (e.g., loss of interest, depressed mood, sleeplessness, lack of energy). Items are rated on a 0 (not at all) to 3 (nearly every day) scale, and higher scores indicate greater and more frequent symptoms of depression.

Mastery. To assess participants' mastery, we used the Pearlin Mastery Scale (Pearlin et al., 1991). This scale assesses a dimension of self-concept reflecting the extent to which people see 
TABLE 2. Sociodemographic characteristics of biomedical doctoral students $(N=69)^{\text {a }}$

\begin{tabular}{lccc}
\hline & $n(\%)$ & M (SD) & Range \\
\hline Age & & $26.5(2.3)$ & $22-33$ \\
Sex: Female & $42(60.9)$ & & \\
Race & & & \\
White/Caucasian & $48(69.6)$ & & \\
Asian & $16(23.2)$ & & \\
Black/African American & $4(5.8)$ & \\
Other & $4(5.8)$ & \\
Middle Eastern/Arab & $2(2.9)$ & \\
Native American/American Indian & $1(1.4)$ & \\
Ethnicity: Hispanic & $12(17.4)$ & \\
Nativity: Born in United States & $50(72.5)$ & \\
Family of origin income & & \\
\$0-\$10,000 & $4(5.8)$ & \\
\$10,001-\$20,000 & $3(4.3)$ & \\
\$20,001-\$40,000 & $7(10.1)$ & \\
\$40,001-\$65,000 & $9(13)$ & \\
\$65,001-\$100,000 & $20(29)$ & \\
> \$100,000 & $26(37.7)$ & \\
Income covers expenses: Yes & $68(98.6)$ & \\
Marital status & & \\
Never married; in relationship & $31(44.9)$ & \\
Never married; not in relationship & $24(34.8)$ & \\
Married & $12(17.4)$ & \\
Separated & $1(1.4)$ & \\
Divorced & & \\
Number of children & & \\
\hline
\end{tabular}

aThere are no missing data regarding sociodemographic characteristics, as all study participants $(N=69)$ completed the sociodemographic questionnaire. To protect the confidentiality of research participants and reduce the likelihood of individual participants being identified, we do not report on the academic programs in which participants were enrolled or the academic years that they were completing at the time of the study.

themselves as being in control of the forces that impact their lives in an important way, through statements such as "I can do just about anything I really set my mind to" and "What happens to me in the future mostly depends on me." Items are rated on a 1 (strongly disagree) to 4 (strongly agree) scale, and higher scores indicate a greater sense of mastery.
Social Support. To measure participants' level of perceived social support, we used the Multidimensional Scale of Perceived Social Support (MSPSS; Zimet et al., 1988). Participants rate items relating to perceived support from significant others (e.g., "There is a special person who is around when I am in need"), family (e.g., "I get the emotional help and support I need from my family"), and friends (e.g. "I can count on my friends when things go wrong"). Items are rated on a 1 (very strongly disagree) to 7 (very strongly agree) scale, and higher scores indicate greater levels of perceived support.

Advisor Relationship. To measure participants' perceived quality of the working relationship between the participant and graduate advisor, we used the Advisory Working Alliance Inventory (AWAI; Schlosser and Gelso, 2001). Participants rate the extent to which they agree with statements about their advisors, such as "My advisor is available when I need her/him" and "My advisor offers me encouragement for my accomplishments." Items are rated on a 1 (strongly disagree) to 5 (strongly agree) scale, and higher scores indicate more positive perceptions of the advisor-advisee relationship.

\section{RESULTS}

\section{Demographic Characteristics}

Table 2 provides an elaborated description of demographic information. Participants were primarily in their mid-20s ( $\mathrm{M}=$ 26.5; $\mathrm{SD}=2.3$ ), white/Caucasian $(n=48 ; 69.6 \%)$, and female ( $n=42 ; 60.9 \%$ ). The majority of participants were currently in a relationship, but not married $(n=31 ; 44.9 \%)$. Our sample included students in most stages of doctoral training (i.e., years 1 through 6); the median time to $\mathrm{PhD}$ completion in biological and biomedical sciences programs at the studied institution from 2013 to 2018 was 5.7 years $(N=523)$. Our sample generally mirrored the overall composition of the enrollees in this program at the time of the study, during which the studied institution's overall population of doctoral students in the biological and biomedical sciences $(N=592)$ was $67.8 \%$ white/Caucasian and $49.2 \%$ female.

\section{Descriptive Statistics of Stress, Burnout,} Depressive Symptoms, and Resource Variables

Table 3 presents descriptive statistics for the GSI-R, SBI, PHQ9, Mastery, MSPSS, and AWAI scales. As GSI-R, PHQ-9, Mastery, and MSPSS scores were not normally distributed, nonparametric tests and approaches were used in analyses.

TABLE 3. Descriptive statistics of stress, outcome, and mediator variables

\begin{tabular}{|c|c|c|c|c|c|c|c|c|}
\hline & \multirow[b]{2}{*}{ Range } & \multirow[b]{2}{*}{ Mean (SD) } & \multirow[b]{2}{*}{ Skew } & \multirow[b]{2}{*}{ Kurtosis } & \multicolumn{2}{|c|}{ Kolmogorov-Smirnov $^{\mathrm{a}}$} & \multicolumn{2}{|c|}{ Shapiro-Wilk } \\
\hline & & & & & Statistic & Sig. & Statistic & Sig. \\
\hline Stress & $23-94$ & $44.96(15.29)$ & 1.04 & 1.20 & 0.110 & 0.038 & 0.930 & 0.001 \\
\hline Academic & $10-49$ & $22.41(7.92)$ & 0.73 & 0.57 & 0.108 & 0.045 & 0.957 & 0.019 \\
\hline Environmental & 4-33 & $13.78(6.37)$ & 1.08 & 0.67 & 0.153 & 0.000 & 0.902 & 0.000 \\
\hline Family/monetary & $1-25$ & $8.77(5.56)$ & 1.02 & 0.22 & 0.176 & 0.000 & 0.889 & 0.000 \\
\hline Burnout & $9-53$ & 28.77 (11.07) & 0.17 & -0.63 & 0.076 & $0.200^{*}$ & 0.980 & 0.339 \\
\hline Depressive symptoms & $0-23$ & $4.64(4.84)$ & 1.73 & 3.40 & 0.176 & 0.000 & 0.823 & 0.000 \\
\hline Mastery & $11-28$ & $22.04(3.70)$ & -0.52 & 0.37 & 0.102 & 0.074 & 0.962 & 0.033 \\
\hline Social support & $42-84$ & $67.86(9.62)$ & -0.72 & 0.37 & 0.135 & 0.003 & 0.949 & 0.007 \\
\hline Advisor relationship & $56-141$ & $105.16(20.76)$ & -0.29 & -0.42 & 0.086 & $0.200 *$ & 0.975 & 0.178 \\
\hline
\end{tabular}

a Kolmogorov-Smirnov test with Lilliefors significance correction. An asterisk ${ }^{*}$ ) indicates this is a lower bound of the true significance level. 
TABLE 4. Zero-order bivariate correlations between stress, outcomes, and mediators ${ }^{\mathrm{a}}$

\begin{tabular}{lcccc}
\hline & 1 & 2 & 3 & 4 \\
1. Stress & & & & \\
2. Burnout & $0.56^{* * *}$ & & & \\
3. Depressive symptoms & $0.50^{* * *}$ & $0.60^{* * *}$ & & \\
4. Mastery & $-0.38^{* *}$ & $-0.59^{* * *}$ & $-0.55^{* * *}$ & \\
5. Social support & -0.22 & -0.19 & $-0.31^{*}$ & $0.39^{* *}$ \\
6. Advisor relationship & -0.23 & $-0.53^{* * *}$ & $-0.41^{* * *}$ & $0.46^{* * *}$ \\
\hline
\end{tabular}

aBivariate correlations are reported as Spearman's rho, except for the correlation between burnout and advisor relationship, which is reported as Pearson's $r$.

$* p<0.05$.

$* * p<0.01$.

$* * * p<0.001$.

Nonparametric statistical methods do not depend on assumptions of normality, and therefore are more robust than parametric methods for statistical inference on nonnormal distributions and smaller sample sizes. For example, instead of Pearson's $r$, we used Spearman's rho for bivariate correlations; and for regression-based analyses, we employed a bootstrapping approach, which estimates test parameters through random sampling with replacement.

\section{Associations between Stress, Burnout, Depressive Symptoms, and Resource Variables}

Table 4 presents zero-order correlations among stress, burnout, depressive symptoms, mastery, social support, and advisor relationship. Nonparametric correlations (i.e., Spearman's rho, $r_{s}$ ) were reported for associations between nonnormal variables, while parametric correlations (i.e., Pearson's $r$ ) were reported for normally distributed variables (i.e., the correlation between burnout and advisor relationship). Stress was positively correlated with both burnout $\left(r_{\mathrm{s}}=0.56, p<0.001\right)$ and depressive symptoms $\left(r_{\mathrm{s}}=0.50, p<0.001\right)$. There was a negative correlation between stress and mastery $\left(r_{\mathrm{s}}=-0.38, p=0.001\right)$. However, there was no significant association between stress and social support $\left(r_{\mathrm{s}}=-0.22, p=0.070\right)$ or stress and advisor relationship $\left(r_{s}=-0.23, p=0.060\right)$. Burnout was negatively correlated with mastery $\left(r_{s}=-0.59, p<0.001\right)$ and advisor relationship $(r=-0.53, p<0.001)$, but not social support $\left(r_{\mathrm{s}}=\right.$ $-0.19, p=0.110)$. Finally, depressive symptoms were negatively correlated with mastery $\left(r_{\mathrm{s}}=-0.55, p<0.001\right)$, social support $\left(r_{s}=-0.31, p=0.010\right)$, and advisor relationship $\left(r_{s}=-0.41, p<\right.$ $0.001)$. Overall, these results support relationships between stress, the mediators of mastery and social support, and the outcomes of burnout and depressive symptoms.

\section{Characterizing Sources of Stress}

To characterize the sources of stress in our sample and understand how these distinct stressors contribute to the outcomes of burnout and depression, we performed linear regressions predicting burnout and depression from the academic, environmental, and family/monetary subscales of the GSI-R. Linear regression analyses model the relationship between a dependent variable and one or more independent, predictor variables, assuming a linear relationship between the variables. Table 5 presents a summary of these analyses. Stress subscales were entered together at a single level, and unstandardized regression coefficients were estimated with 10,000 bootstrap resamples. The bootstrapping approach to regression relies on ran- dom sampling with replacement to estimate regression coefficients and is ideal for smaller sample sizes and nonnormal distributions.

Taken together, academic, environmental, and family/monetary stress explained $31.0 \%$ of the variance in burnout $\left(R^{2}=\right.$ $0.310, F(3,65)=9.75, p<0.001)$. Academic stress stood out as an independent predictor of burnout while controlling for environmental and family/monetary stress $(B=0.50,95 \%$ CI $[0.20$, $0.80]$ ). Academic, environmental, and family/monetary stress together explained $25.5 \%$ of the variance in depressive symptoms $\left(R^{2}=0.255, F(3,65)=7.43, p<0.001\right)$. Family/monetary stress was a significant independent predictor of depressive symptoms while controlling for academic and environmental stress $(B=0.20,95 \%$ CI $[0.02,0.39])$.

\section{Mediation Analysis}

Finally, to investigate direct and indirect effects of stress, mastery, social support, and advisor relationship on the outcomes of burnout and depressive symptoms, we tested mediation hypotheses through a nonparametric bootstrapping approach based on ordinary least-squares regression (Preacher and Hayes, 2004). Mediation tests direct and indirect (mediated) effects of an independent variable on the dependent variable. The direct effect measures the degree to which the independent variable affects the dependent variable while holding the mediator variable constant; whereas the indirect effect measures the extent to which the dependent variable changes while the independent variable is held constant, and the mediator changes by the amount it would have changed had the independent variable increased by one unit. Similar to the previously described bootstrapping approach to regression, bootstrapping with respect to mediation involves random sampling with replacement to estimate direct and indirect effects. Mediation analyses were conducted using model 4 of the PROCESS v. 3.2.01 macro (Hayes, 2017) on SPSS (IBM Corporation, 2015). Mediation models were tested at 95\% $(p<0.05)$ and 99\% $(p<0.01)$ confidence levels, and regression coefficients were estimated with 10,000 bootstrap resamples as recommended by Hayes (2017).

Stress-Burnout Model. Figure 1 presents the multiple mediation model tested with stress as the independent variable and burnout as the dependent variable. Results revealed that the relationship between stress and burnout was partially mediated by mastery (indirect effect [IE] $=0.0954,95 \%$ CI $[0.0303,0.1846]$ ) and advisor relationship (IE $=0.0681,95 \%$ CI $[0.0053,0.1442])$. Social support was not a significant 
TABLE 5. Summary of multiple regressions predicting burnout and depression

\begin{tabular}{|c|c|c|c|c|c|c|c|c|}
\hline \multirow[b]{2}{*}{ Model } & \multirow[b]{2}{*}{$R^{2}$} & \multirow[b]{2}{*}{ Adjusted $R^{2}$} & \multirow[b]{2}{*}{ SE } & \multirow[b]{2}{*}{$F$ change } & \multicolumn{4}{|c|}{ Unstandardized coefficients } \\
\hline & & & & & $B$ & $95 \% \mathrm{CI}$ & SE & $p$ \\
\hline \multicolumn{9}{|l|}{ Dependent variable: Burnout } \\
\hline Step 1 & 0.310 & 0.279 & 9.40 & $9.75 * * *$ & & & & \\
\hline (Constant) & & & & & 10.87 & {$[1.93,17.82]$} & 4.05 & 0.012 \\
\hline Academic stress & & & & & $0.50 * *$ & {$[0.20,0.80]$} & 0.15 & 0.002 \\
\hline Environmental stress & & & & & 0.45 & {$[0.01,0.91]$} & 0.23 & 0.053 \\
\hline Family/monetary stress & & & & & 0.06 & {$[-0.39,0.57]$} & 0.24 & 0.817 \\
\hline \multicolumn{9}{|c|}{ Dependent variable: Depressive symptoms } \\
\hline Step 1 & 0.255 & 0.221 & 4.28 & $7.43^{* * *}$ & & & & \\
\hline (Constant) & & & & & -2.13 & {$[-6.10,0.95]$} & 1.78 & 0.231 \\
\hline Academic stress & & & & & 0.09 & {$[-0.09,0.27]$} & 0.10 & 0.350 \\
\hline Environmental stress & & & & & 0.23 & {$[-0.04,0.48]$} & 0.13 & 0.094 \\
\hline Family/monetary stress & & & & & $0.20 *$ & {$[0.02,0.39]$} & 0.09 & 0.043 \\
\hline
\end{tabular}

mediator between stress and burnout (IE $=-0.0260$, 95\% CI $[-0.0996,0.0071])$.

Stress-Depression Model. Figure 2 presents the multiple mediation model tested with stress as the independent variable and depressive symptoms as the dependent variable. The relationship between stress and depressive symptoms was partially mediated by mastery (IE $=0.0521,95 \%$ CI $[0.0044,0.1086]$ ). The relationship between stress and depressive symptoms was not mediated by advisor relationship (IE $=-0.0001,95 \% \mathrm{CI}$ $[-0.0236,0.0296])$ or social support $(\mathrm{IE}=0.0114,95 \% \mathrm{CI}$ $[-0.0098,0.0366])$.

\section{DISCUSSION}

This pilot study begins to shed light on the interrelationships among stress and distinct adverse outcomes of stress in biomedical doctoral students by characterizing how specific stressors contribute differentially to these outcomes and by testing theo-

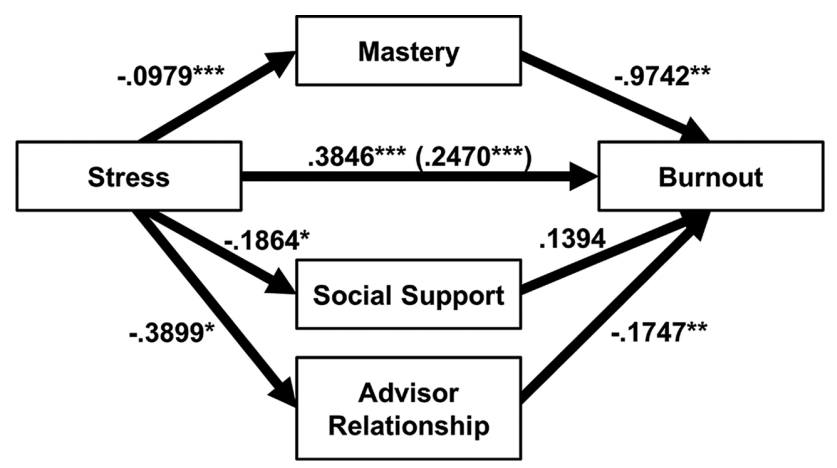

FIGURE 1. Multiple mediation model of stress-burnout relationship with total, direct, and indirect effects. All regression coefficients are unstandardized and generated from 10,000 bootstrap resamples. On the arrow directly connecting stress to burnout, the number outside the parentheses indicates the total effect of stress on burnout, while the number inside the parentheses indicates the direct effect of stress on burnout. ${ }^{*}, p<0.05 ;{ }^{*}, p<0.01$; $* * *, p<0.001$. retical models informed by stress process theory. The results presented here extend the existing literature by using stress process theory to guide mediation modeling, offering possible targets for change accounting for stress-outcome relationships and providing a necessary next step to address the gaps identified by previous research (Tsai and Muindi, 2016). Insights from these analyses can help guide future longitudinal studies in this area, which can offer further evidence replicating and extending our study findings. Additionally, the study advances research on the stress process. Historically, stress process research has focused on depressive outcomes, but has increasingly moved toward examining multiple outcomes of stress (Wheaton, 2009; Aneshensel and Mitchell, 2014). To this end, we tested our hypothesized mediation model with both depressive symptoms and burnout as outcomes.

We found that academic stressors (e.g., writing papers, taking exams, handling the academic workload) were most predictive of burnout, whereas depressive symptoms were best predicted by

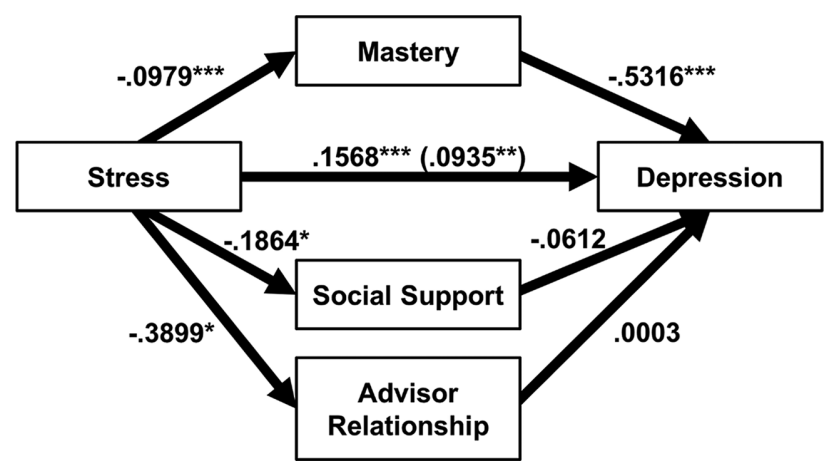

FIGURE 2. Multiple mediation model of stress-depression relationship with total, direct, and indirect effects. All regression coefficients are unstandardized and generated from 10,000 bootstrap resamples. On the arrow directly connecting stress to depression, the number outside the parentheses indicates the total effect of stress on depression, while the number inside the parentheses indicates the direct effect of stress on depression. ${ }^{*}, p<0.05 ;{ }^{* *}, p<0.01 ;{ }^{* *}, p<0.001$. 
family and monetary stressors (e.g., paying monthly expenses, arranging childcare). This is consistent with prior research demonstrating that depressive disorders may be more related to stressful life events in general, whereas burnout is more closely tied to work-related stressors (Plieger et al., 2015). It may also be due in part to the form of the measure we used to assess burnout, the items of which address exhaustion, cynicism, and inadequacy specifically as they apply to the student's graduate program (e.g., "I feel overwhelmed by my graduate program," "I often have feelings of inadequacy in my graduate program"). In contrast, the items on the PHQ-9 refer to global symptoms not restricted to the academic context. These results may be confounded by the fact that our sample is dominated by unmarried (79.7\%) students whose stipends cover their expenses (98.6\%), thus the management of family and financial matters may be less relevant as stressors. Also, several of the environmental stressors on the GSI-R deal with being treated differently by peers and faculty and finding support groups and peers of a similar race and ethnicity on campus. The majority of our sample identified as white/Caucasian (69.6\%), a demographic less likely to experience these kinds of stressors (e.g., Ellis, 2001; Reid and Radhakrishnan, 2003; Attell et al., 2017). This reality highlights the need for recruiting larger samples with increased sociodemographic diversity to examine how stressors distribute across different groups. Despite these shortcomings, our results provide preliminary evidence that distinct stressors contribute to different mental health outcomes in this population.

Applying stress process theory allowed us to test hypotheses regarding mechanisms through which these stressors lead to burnout and depressive symptoms. We found that mastery, a personal resource, was a partial mediator of both the stress-burnout and stress-depression relationships in our sample, even when controlling for social resources in a multiple mediation model (Hayes, 2017). This has implications for future interventions research-perhaps along with reforming training environments, effort should be directed toward improving students' sense of control. It may be that certain stressors inherent to the graduate training environment-such as writing papers and taking exams - cannot and should not be eliminated, as they are essential to graduate education. Instead, programs and policies aimed at bolstering students' perceived control over these aspects of training could be effective in proactively mitigating mental health problems (Freedy and Hobfoll, 2017; de Jonge et al., 2018). Finally, the association between increased stress and diminished mastery in biomedical doctoral students is noteworthy in itself, considering the known impact of mastery on mortality as well as physical and psychological morbidity (e.g., Penninx et al., 1997; Mausbach et al., 2006; Roepke and Grant, 2011).

An interesting finding is that one social resource-the advisor relationship-partially mediated the stress-burnout association, but other forms of support (i.e., friends, family, and significant others) did not. This aligns with prior studies indicating that faculty and program supports are more influential than peer and family supports in predicting doctoral student well-being and satisfaction (Clark et al., 2009; Tompkins et al., 2016). One possible explanation for this finding is that excess academic stressors might be attributed disproportionately to advisors rather than other members of a student's social network, thereby straining the advisor-advisee relationship and subsequently contributing to burnout. Another possible explanation is that, as noted previously, our sample is primarily composed of unmarried students; therefore, family and significant other supports may not be important contributors to mental health in our sample. In any case, our findings add to a growing body of literature identifying the student-advisor relationship as a principal target for improvement, especially considering the association between a functional student-advisor relationship and the student's willingness to seek psychological healthcare (Hyun et al., 2006; Evans et al., 2018).

Our findings are reported with the acknowledgment of multiple important limitations. First, the cross-sectional design precludes any definitive causal conclusions about mediating mechanisms. To fully understand these relationships, it will be necessary to undertake prospective longitudinal studies examining the constructs of stress, burnout, and depression in this population. Second, the sample size $(n=69)$ of this pilot study limited power to detect significant results or to use advanced statistical procedures for mediation analysis, such as structural equation modeling. Third, we studied only one population (biomedical doctoral students), limiting generalizability of our results to other doctoral students. Fourth, participants were recruited based on advertisements, introducing a self-selection bias. Future studies should strive to recruit nationally representative samples of diverse doctoral student populations from multiple institutions. Finally, self-report questionnaires are subject to problems related to response bias, participant insight, and differences in response styles (Paulhus and Vazire, 2007).

Taken together, the current study and our previous report (Nagy et al., 2019) contribute further evidence to a growing body of literature identifying significant mental health problems, including burnout and depression, among biomedical doctoral students. They begin to identify possible reforms to address these problems, including improving the overall training program environment, enhancing advisor relationships, and bolstering mastery.

Our studies highlight several avenues for future research in this area. First, there is a need for powered, longitudinal study designs across cohorts. We recommend that future studies survey students at the beginning of their programs with regard to baseline personal resources (e.g., mastery) and social resources, and then follow this up with periodic monitoring of these resources and psychological well-being throughout students' training. This will help to identify not only how baseline characteristics predict future outcomes, but also how those constructs are affected by the training environment over time and subsequently influence health outcomes.

Second, there is a need to develop and test interventions to improve mental health. Future studies should further examine the construct of mastery in biomedical doctoral students as a target for intervention, along with the student-advisor relationship. One mastery-enhancing intervention that has been validated in student samples is attributional retraining, designed to alter one's attributions for poor performance to more adaptive ones (Weiner, 1985). Among college students, attributional retraining increases perceptions of control (e.g., Hall et al., 2006; Haynes et al., 2006, 2008), while enhancing performance and reducing attrition (Stewart et al., 2011). Fostering a mastery-oriented mindset (i.e., characterized by the belief that success is the result of personal effort and that intelligence can grow rather than being a fixed entity) among doctoral students 
may also lead to more adaptive patterns of learning and resilience in the face of challenges and failure (Elliott and Dweck, 1988; Blackwell et al., 2007).

Few studies have rigorously tested interventions to enhance the student-advisor relationship. One study of eight $\mathrm{PhD}$ students and their two advisors tested a gratitude-based intervention, involving bringing greater attention to gratitude in relationships along with executing a specific gratitude practice (Howells et al., 2017). By the end of the study period, both students and advisors reported positive effects on their interpersonal and personal well-being, improved trust and communication in the student-advisor relationship, and increased motivation and productivity. Though this was a small, qualitative study, it represents a potential targeted intervention to enhance student-advisor relationships that can be scaled at low cost. Furthermore, while we measured the perceived quality of the advising relationship from the student's perspective in this study, we did not assess the advisor's perspective of the relationship, nor did we assess the quality of advising. Future studies should comprehensively examine the student-advisor relationship to aid in intervention development.

Finally, though we have identified two potential targetspersonal resources such as mastery and student-advisor dyads-these "micro" levels of social interaction are not the sole contributors to student well-being (Wheaton et al., 2013). We propose that future studies examine how other levels of interaction contribute to a doctoral student's mental health, inclusive of "meso" (e.g., the overall program climate; Veilleux et al., 2012) and "macro" (e.g., national competition for faculty research positions; Alberts et al., 2014) contexts. Similarly, while we studied supports at the personal level (with the MSPSS) and the advisor-advisee level (with the AWAI), future research should examine the differential impacts of support at other levels (e.g., lab group, department, graduate school, institution-wide) on mental health outcomes. Additionally, other personal resources-such as resilience (Steinhardt and Dolbier, 2008), optimism (Kleiman et al., 2017), and autonomy (Deci and Ryan, 1987; Evans and Boucher, 2015; Kusurkar and Croiset, 2015)—may contribute significantly to student well-being. These additional, unmeasured factors may account for some of the unexplained variance in the stress process mediation models and may represent future avenues of study.

As we improve our understanding of the prevalence, antecedents, and consequences of mental health problems in doctoral students, administrators in graduate programs across the country are likely to be poised to respond to these issues. However, given the current dearth of high-quality interventions research, they may lack clarity on how to use their limited resources in doing so. Our study represents a first step in providing such guidance, and we hope to encourage further study in this area for the sake of future scientists.

\section{ACKNOWLEDGMENTS}

We thank the Office of the Dean within the School of Medicine at our institution for funding this research. Additionally, we thank the research personnel who aided our team with conducting the research protocol with study participants-without you this project would not have been possible; namely, we acknowledge the contributions made by Kibby McMahon, Angela Pisoni, Shelley Lanpher, Daniel Seed, and Alma Vázquez-Smith.

\section{REFERENCES}

Alberts, B., Kirschner, M. W., Tilghman, S., \& Varmus, H. (2014). Rescuing US biomedical research from its systemic flaws. Proceedings of the National Academy of Sciences USA, 111(16), 5773-5777. https://doi.org/10.1073/ pnas.1404402111

American Psychiatric Association. (2013). Diagnostic and statistical manual of mental disorders (5th ed.). Arlington, VA: American Psychiatric Publishing. https://doi.org/10.1176/appi.books.9780890425596

Aneshensel, C. S., \& Mitchell, U. A. (2014). The stress process: Its origins evolution, and future. In Johnson, R. J., Turner, R. J., \& Link, B. G. (Eds.), Springer briefs in sociology. Sociology of mental health: Selected topics from forty years, 1970s-2010s (pp. 53-74). New York: Springer Science + Business Media. http://dx.doi.org/10.1007/978-3-319-07797 -0_3

Attell, B. K., Brown, K. K., \& Treiber, L. A. (2017). Workplace bullying, perceived job stressors, and psychological distress: Gender and race differences in the stress process. Social Science Research, 65, 210-221. https://doi .org/10.1016/j.ssresearch.2017.02.001

Bakker, A. B., \& Demerouti, E. (2007). The job demands-resources model: State of the art. Journal of Managerial Psychology, 22(3), 309-328. https://doi.org/10.1108/02683940710733115

Berry, J. M., \& West, R. L. (1993). Cognitive self-efficacy in relation to personal mastery and goal setting across the life span. International Journal of Behavioral Development, 16(2), 351-379. https://doi.org/10.1177/ 016502549301600213

Bianchi, R., Schonfeld, I. S., \& Laurent, E. (2015). Burnout-depression overlap: A review. Clinical Psychology Review, 36, 28-41. https://doi .org/10.1016/j.cpr.2015.01.004

Bianchi, R., Schonfeld, I. S., Vandel, P., \& Laurent, E. (2017). On the depressive nature of the "burnout syndrome": A clarification. European Psychiatry 41, 109-110. https://doi.org/10.1016/j.eurpsy.2016.10.008

Blackwell, L. S., Trzesniewski, K. H., \& Dweck, C. S. (2007). Implicit theories of intelligence predict achievement across an adolescent transition: A longitudinal study and an intervention. Child Development, 78(1), 246-263. https://doi.org/10.1111/j.1467-8624.2007.00995.x

Clark, H., Murdock, N. L., \& Koetting, K. (2009). Predicting burnout and career choice satisfaction in counseling psychology graduate students. Counseling Psychologist, 37(4), 580-606. https://doi.org/10.1177/ 0011000008319985

Cohen, S. (2004). Social relationships and health. American Psychologist 59(8), 676. https://doi.org/10.1037/0003-066X.59.8.676

Cohen, S., Kamarck, T., \& Mermelstein, R. (1983). A global measure of perceived stress. Journal of Health and Social Behavior, 24(4), 385-396. https://doi.org/10.2307/2136404

Cohen, S., \& Wills, T. A. (1985). Stress, social support, and the buffering hypothesis. Psychological Bulletin, 98(2), 310. https://doi.org/10.1037/0033 $-2909.98 .2 .310$

Cornér, S., Löfström, E., \& Pyhältö, K. (2017). The relationships between doctoral students' perceptions of supervision and burnout. International Journal of Doctoral Studies, 12, 91-106. https://doi.org/10.28945/3754

Deci, E. L., \& Ryan, R. M. (1987). The support of autonomy and the control of behavior. Journal of Personality and Social Psychology, 53(6), 1024. https://doi.org/10.1037/0022-3514.53.6.1024

de Jonge, M., Bockting, C. L., van Oppen, P., Van, H. L., Peen, J., Kikkert, M. J., $\&$ Dekker, J. J. (2018). The association between the number of previous episodes and modifiable vulnerability factors in remitted patients with recurrent depression. PLOS ONE, 13(11), e0206495. https://doi.org/ 10.1371/journal.pone.0206495

Devine, K., \& Hunter, K. H. (2017). PhD student emotional exhaustion: The role of supportive supervision and self-presentation behaviours. Innovations in Education and Teaching International, 54(4), 335-344. https:// doi.org/10.1080/14703297.2016.1174143

Dupéré, V., Leventhal, T., Dion, E., Crosnoe, R., Archambault, I., \& Janosz, M. (2015). Stressors and turning points in high school and dropout: A stress process, life course framework. Review of Educational Research, 85(4), 591-629. https://doi.org/10.3102/0034654314559845

Dyrbye, L. N., Thomas, M. R., \& Shanafelt, T. D. (2005). Medical student distress: Causes, consequences, and proposed solutions. Mayo Clinic Proceedings, 80(12), 1613-1622. https://doi.org/10.4065/80.12.1613 
Elliott, E. S., \& Dweck, C. S. (1988). Goals: An approach to motivation and achievement. Journal of Personality and Social Psychology, 54(1), 5. https://doi.org/10.1037/0022-3514.54.1.5

Ellis, E. M. (2001). The impact of race and gender on graduate school socialization, satisfaction with doctoral study, and commitment to degree completion. Western Journal of Black Studies, 25(1), 30.

Evans, M., \& Boucher, A. R. (2015). Optimizing the power of choice: Supporting student autonomy to foster motivation and engagement in learning Mind, Brain, and Education, 9(2), 87-91. https://doi.org/10.1111/ mbe.12073

Evans, T. M., Bira, L., Gastelum, J. B., Weiss, L. T., \& Vanderford, N. L. (2018). Evidence for a mental health crisis in graduate education. Nature Biotechnology, 36(3), 282. https://doi.org/10.1038/nbt.4089

Ferreira, M. (2003). Gender issues related to graduate student attrition in two science departments. International Journal of Science Education, 25(8), 969-989. https://doi.org/10.1080/09500690305026

Freedy, J., \& Hobfoll, S. E. (2017). Conservation of resources: A general stress theory applied to burnout. In Schaufeli, W. B., Maslach, C., \& Marek, T. (Eds.), Professional burnout (pp. 115-129). Routledge.

Fuhrmann, C. N., Halme, D. G., O'Sullivan, P. S., \& Lindstaedt, B. (2011). Improving graduate education to support a branching career pipeline: Recommendations based on a survey of doctoral students in the basic biomedical sciences. CBE-Life Sciences Education, 10(3), 239-249. https:// doi.org/10.1187/cbe.11-02-0013

Goldstein, D. S., \& Kopin, I. J. (2007). Evolution of concepts of stress. Stress, 10(2), 109-120. https://doi.org/10.1080/10253890701288935

Hall, N. C., Perry, R. P., Chipperfield, J. G., Clifton, R. A., \& Haynes, T. L. (2006). Enhancing primary and secondary control in achievement settings through writing-based attributional retraining. Journal of Social and Clinical Psychology, 25(4), 361-391. https://doi.org/10.1521/jscp.2006 .25.4.361

Hammen, C. (2005). Stress and depression. Annual Review of Clinical Psychology, 1, 293-319. https://doi.org/10.1146/annurev.clinpsy.1.102803 143938

Hawley, L. L., Ho, M. H. R., Zuroff, D. C., \& Blatt, S. J. (2007). Stress reactivity following brief treatment for depression: Differential effects of psychotherapy and medication. Journal of Consulting and Clinical Psychology, 75(2), 244. https://doi.org/10.1037/0022-006X.75.2.244

Hayes, A. F. (2017). Introduction to mediation, moderation, and conditional process analysis: A regression-based approach. New York: Guilford.

Haynes, T. L., Daniels, L. M., Stupnisky, R. H., Perry, R. P., \& Hladkyj, S. (2008). The effect of attributional retraining on mastery and performance motivation among first-year college students. Basic and Applied Social Psychology, 30(3), 198-207. https://doi.org/10.1080/01973530802374972

Haynes, T. L., Ruthig, J. C., Perry, R. P., Stupnisky, R. H., \& Hall, N. C. (2006). Reducing the academic risks of over-optimism: The longitudinal effects of attributional retraining on cognition and achievement. Research in Higher Education, 47(7), 755. https://doi.org/10.1007/s11162-006-9014-7

Hefner, J., \& Eisenberg, D. (2009). Social support and mental health among college students. American Journal of Orthopsychiatry, 79(4), 491-499. https://doi.org/10.1037/a0016918

Howells, K., Stafford, K., Guijt, R., \& Breadmore, M. (2017). The role of gratitude in enhancing the relationship between doctoral research students and their supervisors. Teaching in Higher Education, 22(6), 621-638. https://doi.org/10.1080/13562517.2016.1273212

Hyun, J. K., Quinn, B. C., Madon, T., \& Lustig, S. (2006). Graduate student mental health: Needs assessment and utilization of counseling services. Journal of College Student Development, 47(3), 247-266. https://doi .org/10.1353/csd.2006.0030

IBM Corporation. (2015). IBM SPSS statistics for Windows (Version 23.0). Armonk, NY

Jenaabadi, H., Nastiezaie, N., \& Safarzaie, H. (2017). The relationship of academic burnout and academic stress with academic self-efficacy among graduate students. New Educational Review, 49(3), 65-76.

Kleiman, E. M., Chiara, A. M., Liu, R. T., Jager-Hyman, S. G., Choi, J. Y., \& Alloy, L. B. (2017). Optimism and well-being: A prospective multi-method and multi-dimensional examination of optimism as a resilience factor following the occurrence of stressful life events. Cognition and Emotion, 31(2), 269-283. https://doi.org/10.1080/02699931.2015.1108284
Koolhaas, J. M., Bartolomucci, A., Buwalda, B. D., De Boer, S. F., Flügge, G., Korte, S. M., ... \& Richter-Levin, G. (2011). Stress revisited: A critical evaluation of the stress concept. Neuroscience \& Biobehavioral Reviews, 35(5), 1291-1301. https://doi.org/10.1016/j.neubiorev.2011.02.003

Kroenke, K., Spitzer, R. L., \& Williams, J. B. (2001). The PHQ-9: Validity of a brief depression severity measure. Journal of General Internal Medicine, 16(9), 606-613. https://doi.org/10.1046/j.1525-1497.2001.016009606.x

Kusurkar, R. A., \& Croiset, G. (2015). Autonomy support for autonomous motivation in medical education. Medical Education Online, 20(1), 27951. https://doi.org/10.3402/meo.v20.27951

Leskela, U., Rytsala, H., Komulainen, E., Melartin, T., Sokero, P., Lestela-Mielonen, P., \& Isometsa, E. (2006). The influence of adversity and perceived social support on the outcome of major depressive disorder in subjects with different levels of depressive symptoms. Psychological Medicine, 36(6), 779-788. https://doi.org/10.1017/S0033291706007276

Levecque, K., Anseel, F., De Beuckelaer, A., Van der Heyden, J., \& Gisle, L. (2017). Work organization and mental health problems in PhD students. Research Policy, 46(4), 868-879. https://doi.org/10.1016/ j.respol.2017.02.008

Marshall, G. N., \& Lang, E. L. (1990). Optimism, self-mastery, and symptoms of depression in women professionals. Journal of Personality and Social Psychology, 59(1), 132. https://doi.org/10.1037/0022-3514.59.1.132

Maslach, C., Jackson, S. E., Leiter, M. P., Schaufeli, W. B., \& Schwab, R. L. (1986). Maslach burnout inventory (Vol. 21, pp. 3463-3464). Palo Alto, CA: Consulting Psychologists Press.

Maslach, C., \& Leiter, M. P. (2016). Understanding the burnout experience: Recent research and its implications for psychiatry. World Psychiatry, 15(2), 103-111. https://doi.org/10.1002/wps.20311

Maslach, C., Schaufeli, W. B., \& Leiter, M. P. (2001). Job burnout. Annual Review of Psychology, 52(1), 397-422. https://doi.org/10.1146/annurev psych.52.1.397

Mausbach, B. T., Patterson, T. L., Känel, R. V., Mills, P. J., Ancoli-Israel, S., Dimsdale, J. E., \& Grant, I. (2006). Personal mastery attenuates the effect of caregiving stress on psychiatric morbidity. Journal of Nervous and Mental Disease, 194(2), 132-134. https://doi.org/10.1097/01. nmd.0000198198.21928.e7

Mausbach, B. T., Patterson, T. L., Känel, R. V., Mills, P. J., Dimsdale, J. E., Ancoli-Israel, S., \& Grant, I. (2007). The attenuating effect of personal mastery on the relations between stress and Alzheimer caregiver health: A fiveyear longitudinal analysis. Aging \& Mental Health, 11(6), 637-644. https:// doi.org/10.1080/13607860701787043

Mazure, C. M. (1998). Life stressors as risk factors in depression. Clinical Psychology: Science and Practice, 5(3), 291-313. https://doi .org/10.1111/j.1468-2850.1998.tb00151.x

Nagy, G. A., Fang, C. M., Hish, A. J., Kelly, L., Nicchitta, C. V., Dzirasa, K., \& Rosenthal, M. Z. (2019). Burnout and mental health problems in biomedical doctoral students. CBE-Life Sciences Education, 18(2), ar27. https:// doi.org/10.1187/cbe.18-09-0198

Nicolaisen, M., Moum, T., \& Thorsen, K. (2017). Mastery and depressive symptoms: How does mastery influence the impact of stressors from midlife to old age? Journal of Aging and Health, 30(7), 1084-1107.

Parker, P. D., \& Salmela-Aro, K. (2011). Developmental processes in school burnout: A comparison of major developmental models. Learning and Individual Differences, 21(2), 244-248. https://doi.org/10.1016/j.lindif.2011.01.005

Paulhus, D. L., \& Vazire, S. (2007). The self-report method. Handbook of Research Methods in Personality Psychology, 1, 224-239.

Pearlin, L. I. (1989). The sociological study of stress. Journal of Health and Social Behavior, 241-256. https://doi.org/10.2307/2136956

Pearlin, L. I. (2009). The life course and the stress process: Some conceptual comparisons. Journals of Gerontology Series B: Psychological Sciences and Social Sciences, 65(2), 207-215. https://doi.org/10.1093/geronb/ gbp106

Pearlin, L. I., \& Bierman, A. (2013). Current issues and future directions in research into the stress process. In Aneshensel, C. S., Phelan, J. C., \& Bierman, A. (Eds.), Handbook of the sociology of mental health (pp. 325340). New York: Springer Science + Business Media. http://dx.doi.org/ 10.1007/978-94-007-4276-5_16

Pearlin, L., Lieberman, M., Menaghan, E., \& Mullan, J. (1991). Mastery scale. In Wrightsman, L. S., Robinson, J. P., Shaver, P. R., \& Andrews, F. M. (Eds.), 
Measures of personality and social psychological attitudes. San Diego: Academic Press.

Pearlin, L. I., Menaghan, E. G., Lieberman, M. A., \& Mullan, J. T. (1981). The stress process. Journal of Health and Social Behavior, 22(4), 337-356. https://doi.org/10.2307/2136676

Peltonen, J. A., Vekkaila, J., Rautio, P., Haverinen, K., \& Pyhältö, K. (2017). Doctoral students' social support profiles and their relationship to burnout, drop-out intentions, and time to candidacy. International Journal of Doctoral Studies, 12, 157-173. https://doi.org/10.28945/3792

Penninx, B. W., Van Tilburg, T., Kriegsman, D. M., Deeg, D. J., Boeke, A. J. P., \& van Eijk, J. T. M. (1997). Effects of social support and personal coping resources on mortality in older age: The Longitudinal Aging Study Amsterdam. American Journal of Epidemiology, 146(6), 510-519. https:// doi.org/10.1093/oxfordjournals.aje.a009305

Pizzagalli, D. A. (2014). Depression, stress, and anhedonia: Toward a synthesis and integrated model. Annual Review of Clinical Psychology, 10, 393423. https://doi.org/10.1146/annurev-clinpsy-050212-185606

Plieger, T., Melchers, M., Montag, C., Meermann, R., \& Reuter, M. (2015). Life stress as potential risk factor for depression and burnout. Burnout Research, 2(1), 19-24. https://doi.org/10.1016/j.burn.2015.03.001

Preacher, K. J., \& Hayes, A. F. (2004). SPSS and SAS procedures for estimating indirect effects in simple mediation models. Behavior Research Methods, Instruments, \& Computers, 36(4), 717-731. https://doi.org/10.3758/ BF03206553

Prelow, H. M., Mosher, C. E., \& Bowman, M. A. (2006). Perceived racial discrimination, social support, and psychological adjustment among African American college students. Journal of Black Psychology, 32(4), 442-454. https://doi.org/10.1177/0095798406292677

Pudrovska, T., Schieman, S., Pearlin, L. I., \& Nguyen, K. (2005). The sense of mastery as a mediator and moderator in the association between economic hardship and health in late life. Journal of Aging and Health, 17(5), 634-660. https://doi.org/10.1177/0898264305279874

Qualtrics. (2013). QualtricsXM of the Qualtrics Research Suite. Provo, UT. Retrieved August 13, 2019, from www.qualtrics.com

Reid, L. D., \& Radhakrishnan, P. (2003). Race matters: The relation between race and general campus climate. Cultural Diversity and Ethnic Minority Psychology, 9(3), 263. https://doi.org/10.1037/1099-9809.9.3.263

Rigg, J., Day, J., \& Adler, H. (2013). Emotional exhaustion in graduate students: The role of engagement, self-efficacy and social support. Journal of Educational and Developmental Psychology, 3(2), 138. https://doi .org/10.5539/jedp.v3n2p138

Rocha-Singh, I. A. (1994). Perceived stress among graduate students: Development and validation of the graduate stress inventory. Educational and Psychological Measurement, 54(3), 714-727. https://doi.org/10.1177/ 0013164494054003018

Roepke, S. K., \& Grant, I. (2011). Toward a more complete understanding of the effects of personal mastery on cardiometabolic health. Health Psychology, 30(5), 615. https://doi.org/10.1037/a0023480

Salmela-Aro, K., Kiuru, N., Leskinen, E., \& Nurmi, J. E. (2009). School Burnout Inventory (SBI) reliability and validity. European Journal of Psychological Assessment, 25(1), 48-57. https://doi.org/10.1027/1015-5759.25.1.48

Schaufeli, W., \& Enzmann, D. (1998). The burnout companion to study and practice: A critical analysis. Boca Raton, FL: CRC Press.
Schaufeli, W. B., Leiter, M. P., \& Maslach, C. (2009). Burnout: 35 years of research and practice. Career Development International, 14(3), 204-220. https://doi.org/10.1108/13620430910966406

Schlosser, L. Z., \& Gelso, C. J. (2001). Measuring the working alliance in advisor-advisee relationships in graduate school. Journal of Counseling Psychology, 48(2), 157. https://doi.org/10.1037/0022-0167.48.2.157

Schneiderman, N., Ironson, G., \& Siegel, S. D. (2005). Stress and health: Psychological, behavioral, and biological determinants. Annual Review of Clinical Psychology, 1, 607-628. https://doi.org/10.1146/annurev.clinpsy .1.102803.144141

Steinhardt, M., \& Dolbier, C. (2008). Evaluation of a resilience intervention to enhance coping strategies and protective factors and decrease symptomatology. Journal of American College Health, 56(4), 445-453. https://doi.org/10.3200/JACH.56.44.445-454

Stewart, T. L. H., Clifton, R. A., Daniels, L. M., Perry, R. P., Chipperfield, J. G., \& Ruthig, J. C. (2011). Attributional retraining: Reducing the likelihood of failure. Social Psychology of Education, 14(1), 75-92. https://doi org/10.1007/s11218-010-9130-2

Thoits, P. A. (2010). Stress and health: Major findings and policy implications. Journal of Health and Social Behavior, 51(suppl 1), S41-S53. https://doi .org/10.1177/0022146510383499

Tompkins, K. A., Brecht, K., Tucker, B., Neander, L. L., \& Swift, J. K. (2016). Who matters most? The contribution of faculty, student-peers, and outside support in predicting graduate student satisfaction. Training and Education in Professional Psychology, 10(2), 102. https://doi.org/10.1037/tep0000115

Tsai, J. W., \& Muindi, F. (2016). Towards sustaining a culture of mental health and wellness for trainees in the biosciences. Nature Biotechnology, 34(3), 353. https://doi.org/10.1038/nbt.3490

Veilleux, J. C., January, A. M., VanderVeen, J. W., Reddy, L. F., \& Klonoff, E. A. (2012). Perceptions of climate in clinical psychology doctoral programs: Development and initial validation of the Graduate Program Climate Scale. Training and Education in Professional Psychology, 6(4), 211. https://doi.org/10.1037/a0030303

Wang, X., Cai, L., Qian, J., \& Peng, J. (2014). Social support moderates stress effects on depression. International Journal of Mental Health Systems, 8(1), 41. https://doi.org/10.1186/1752-4458-8-41

Weiner, B. (1985). An attributional theory of achievement motivation and emotion. Psychological Review, 92(4), 548. https://doi.org/10.1037/0033 $-295 \times .92 .4 .548$

Wheaton, B. (2009). The stress process as a successful paradigm. In Avison W., Aneshensel, C., Schieman, S., \& Wheaton, B. (Eds.), Advances in the conceptualization of the stress process (pp. 231-252). New York: Springer. https://doi.org/10.1007/978-1-4419-1021-9_13

Wheaton, B., Young, M., Montazer, S., \& Stuart-Lahman, K. (2013). Social stress in the twenty-first century. In Aneshensel, C. S., Phelan, J. C., \& Bierman, A. (Eds.), Handbook of the sociology of mental health (pp. 299323). Dordrecht, Netherlands: Springer. https://doi.org/10.1007/978-94 -007-4276-5_15

You, F. H., \& Chen, Z. J. (2012). Impacts of academic stress, self-efficacy and optimism on suicide ideation of doctoral students. Chinese Journal of Clinical Psychology, 20, 662-665.

Zimet, G. D., Dahlem, N. W., Zimet, S. G., \& Farley, G. K. (1988). The multidimensional scale of perceived social support. Journal of Personality Assessment, 52(1), 30-41. https://doi.org/10.1207/s15327752jpa5201_2 